\title{
Hipólito Unanue y el proceso de construcción del discurso epidemiológico peruano
}

\author{
Juan-Pablo Murillo ${ }^{1}$
}

Resumen

Palabras clave

\begin{abstract}
El siguiente ensayo establece una primera aproximación al estudio de la influencia del pensamiento de Hipólito Unanue en la construcción del discurso epidemiológico peruano. Luego de describir los aspectos más generales de las ideas de Unanue sobre los procesos de propagación de enfermedades, se discute cómo, a principios del siglo $X X$, en medio del debate sobre los problemas de población y las diversas posibilidades de desarrollo del país, diversos autores retoman las ideas de Unanue, erigido como héroe cultural de la colectividad médica. Se analiza su influencia en la obra de intelectuales, como Paz Soldán, Olaechea y Lastres analizando las diversas particularidades del proceso de decodificación de su pensamiento y como este permitió el desarrollo de un proceso de identidad asociado a la formación de una 'conciencia peruana', es decir, de una forma particular de mirar y transformar el mundo. Esta forma sistémica de abordar la complejidad del Perú es una de las características del desarrollo inicial de la epidemiología peruana, donde confluyen la Historia, la Geografía, la Sociología, la Antropología y la Eugenia para trazar explicaciones propias a los procesos de propagación de las enfermedades en el Perú.

Unanue, Hipólito; Perú, historia de la medicina; epidemiología; población; eugenia.
\end{abstract}

\section{Hipolito Unanue and thePeruvian epidemiology discourse building process}

Abstract

This essay is a first approximation to the study of Hipolito Unanue's thinking influence on the Peruvian epidemiology discourse construction. After describing general aspects of Unanue's thought on the processes of disease propagation, we discuss how at the beginning of the $X X$ century, in middle of the debate on the community problems and the various possibilities of the nation's development, different authors retake Unanue's ideas, who had already been raised up as a cultural hero of the medical community. We analyze his influence in the work of intellectuals like Paz Soldan, Olaechea and Lastres analyzing the diverse particularities of their thinking decodifying process and how this allowed the development of an identity process linked to the making of a 'Peruvian conscience', that is, of a particular way of seeing and transforming the world. This systemic way of approaching Peru's complexity is one of the characteristics of the initial development of Peruvian epidemiology, where History, Geography, Sociology, Anthropology, and Eugenics converge to outline explanations proper to the diseases propagation processes in Peru.

1 Profesor Auxiliar del Departamento Académico de Medicina Preventiva y Salud Pública, Facultad de Medicina de San Fernando, Universidad Nacional Mayor de San Marcos. Lima, Perú.
Keywords: Unanue, Hipolito; Peru, history of medicine; epidemiology; population; eugenics.

\section{Introducción}

En la tradición médica peruana, la Epidemiología es una de las pocas disciplinas en las cuales desde etapas muy tempranas de su introducción al país, se planteó una tradición de pensamiento local. Diversos autores, como Carlos Enrique Paz Soldán o Hugo Pesce, reivindicaron la posibilidad de una mirada propia de los procesos de propagación de enfermedades. Alarcón expresa este consenso cuando sitúa a Cosme Bueno e Hipólito Unanue como elementos protagónicos en la construcción de las corrientes de pensamiento epidemiológico, reivindicando una "tradición epidemiológica, de indudable raigambre hipocrática, que ha sido cuidadosamente seguida por los médicos peruanos, y que se caracteriza por una rica descripción del proceso mórbido y del ambiente geográfico, social y cultural donde se desarrolla, recogiendo no solo datos exactos sino incluso referencias de costumbres y mitos" $\left.{ }^{1}\right)$.

Sin embargo, a pesar del unánime consenso en torno a esta tradición, no existen estudios acerca de los procesos socio-históricos que permitieron la construcción del discurso epidemiológico en el Perú, 
menos aún cómo se integró y decodificó los aportes de quienes inicialmente comenzaron a adquirir el rol de héroes culturales del naciente colectivo de profesionales que iniciaron la reflexión y la praxis de la salud colectiva peruana a inicios del siglo XX. En ese sentido, el propósito de este ensayo, es establecer una primera aproximación al rol del pensamiento de Hipólito Unanue en la construcción del discurso epidemiológico peruano.

A pesar de la abundante literatura al respecto, no existen estudios sistemáticos de las ideas de Unanue respecto a los procesos de propagación de enfermedades. Si bien el objeto del siguiente estudio no es desarrollar en toda su extensión sus ideas a este respecto, es importante establecer sus componentes más importantes a efectos de comprender el sentido de la lectura y posterior decodificación por parte de los primeros epidemiólogos locales de las ideas de este ilustre pensador peruano.

\section{Decadencia y restauración del Perú. Una propuesta de modernización}

El núcleo del pensamiento poblacional de Unanue se encuentra en la oración inaugural del Anfiteatro Anatómico, en la Real Universidad de San Marcos, el 21 de noviembre de 1792. Aquí traza el cuadro de un país en crisis y decadencia social y económica, por la falta de mano de obra para desplegar actividades productivas:

“De que sirven los pueblos arruinados?, ¿De qué los países fértiles sin agricultores?, ¿De que las minas poderosas sin operarios? Faltando los brazos que aren los campos, rompan las entrañas de la tierra y den impulso a las artes y al comercio, la miseria hará gemir sin recurso el país mismo donde la liberal naturaleza ha derramado los tesoros de su inagotable fecundidad..." ( $\left.{ }^{2}\right)$

Las poblaciones arrasadas por epidemias, postradas por la miseria, podían ser rescatadas de su lamentable situación mediante la práctica de la medicina ilustrada, armada con los recursos de la anatomía, podría multiplicar su población, en suficiente número para generar industrias e impulsar el progreso del Perú:

"Conmovida la tierra que cubre a esta por un número triplicado de brazos, cada cerro sería un nuevo Potosí, cuyos desperdicios podrían enriquecer una parte del globo... He aquí la feliz, la venturosa suerte que, perdida en el Perú por la ignorancia de la anatomía, va a restaurarle la ilustración y la práctica de esta ciencia benéfica..." (2)
La Figura 1 es un esquema que representa el diagnóstico y la propuesta de Unanue respecto a los problemas de población y su relación con una propuesta de desarrollo del país.

Es claro que el interés de Unanue en intervenir sobre la salud de la población estaba de la mano con un proyecto de desarrollo basado en el carácter 'civilizador' del comercio. Gracias al comercio «los pueblos se frotan y electrizan recíprocamente», lo cual hace que todo 'tenga vida'. En ese sentido, nos propone una visión casi mesiánica del comercio internacional como estrategia para el desarrollo del Perú. Ella coincidía con las teorías mercantilistas que en un determinado momento predominaron en el pensamiento europeo, que postulaban que el incremento del número de habitantes aceleraría el intercambio comercial. Sin embargo, como lo señalan varios autores, cuando Unanue despliega estas ideas en nuestro medio, las teorías respecto al desarrollo económico habían cambiado radicalmente gracias a los postulados de los fisiócratas y de Adam Smith, quienes sostenían que la riqueza de las naciones eran determinadas por el grado de modernización tecnológica y la división del trabajo productivo $\left({ }^{3}\right)$.

\section{El clima de Lima. \\ Una visión alternativa del mundo}

Es importante no perder de vista que el pensamiento de Unanue respecto al hombre y al ambiente americano estaba en franca oposición con las ideas imperantes en Europa. En ese sentido, se expresa de una manera transparente cuando sostiene:

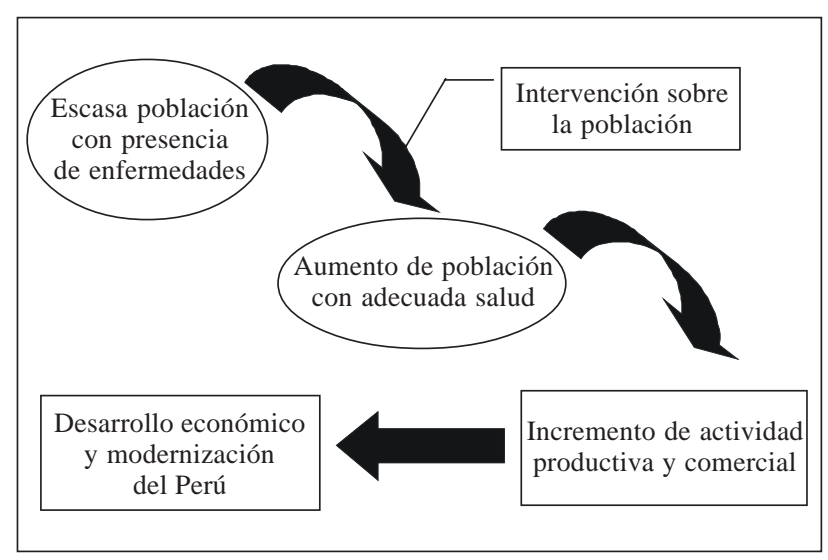

Figura 1. Proceso de modernización del Perú según Unanue. 
“Al Perú no corresponde la espantosa pintura que de la América ha hecho la exaltada imaginación de algunos filósofos ultramarinos. Parece que mojaron su pincel en amargos y negros tintes para retratar a estas regiones afortunadas como a un suelo ingrato, negado a las bendiciones del cielo..." $\left({ }^{4}\right)$

Por ello, no es de extrañar que el núcleo de las reflexiones de Unanue esté orientado a deslindar con las cuatro proposiciones de Buffón, que establecían las características diferenciales entre los animales del nuevo y viejo mundo. Esto es central para poder establecer una argumentación orientada a mostrar la igualdad del hombre americano respecto al europeo, en un escenario en el que pensadores como De Pawn consideraban a los americanos brutos, seres que no respetan el orden ni las leyes, ligeramente superiores a los animales porque tienen el uso de las manos y la lengua; son realmente inferiores al menor de los europeos; privados a su vez de inteligencia y de perfectibilidad, no obedecen más que a los impulsos de su instinto * $\left({ }^{5,6}\right)$.

En ese sentido, Unanue propone una tesis vanguardista alternativa al consenso europeo, al afirmar que el hombre desciende de un antepasado común, pero la diversidad de climas, usos y alimentos han generado a su vez una gran variedad de facciones y propiedades que crean la falsa percepción de diferentes orígenes. Para desplegar su pensamiento alternativo, adopta un concepto específico de raza, aludiendo a un conjunto de características estructurales y funcionales particulares de grupos humanos originarios de un área geográfica específica, distinguiendo de acuerdo a ello cuatro razas: La asiática, la europea, la americana y la africana $\left({ }^{7}\right)$.

Esta categoría fue uno de los ejes de análisis en el cual Unanue desarrolló sus conceptos de propagación de enfermedades. La raza determinaba no sólo el lugar del individuo en la sociedad, sino sus capacidades de adaptación al ambiente y su vulnerabilidad a ciertas enfermedades:

"Aunque el abandono y miseria en que viven los indios sea la causa principal del gran número que muere en tiempos epidémicos, mientras que es pequeña comparativamente la mortandad de blancos, negros y castas; debe también considerarse que en ellos, como originarios del país, es mayor la relaxación de sus fibras y debilidad nerviosa y abunda más la cólera. Decía discretamente el Dr. Bueno, que el indio tenía los huesos duros y las carnes blandas. Con dificultad se les rompe la cabeza de un garrotazo, y la menor fiebre los postra. El catarro los conduce a la tisis, se hacen casi incurables las disenterías en ellos, las tercianas los estropean, y los arruinan el sarampión y las viruelas..." $\left(^{4}\right)$

Sin embargo, para Unanue las diferencias entre las diversas razas, podían ser soslayadas a partir de la educación, la cual podía, a través de la moral, desplegar las capacidades de los seres humanos y contrarrestar las influencias nefastas del ambiente.

Un elemento que ha generado controversia es el hecho que a la par de propugnar la igualdad del hombre americano respecto al europeo y cómo la educación y la mejora de las condiciones de vida podían contribuir al desarrollo de las capacidades de los razas aborígenes de manera similar a las poblaciones del viejo mundo, Unanue desarrolla una taxonomía de las diferentes castas que habitan Lima, donde se muestra todo un conjunto de gradaciones que van del blanco, el 'color primitivo del hombre' abarcando hasta su 'última degeneración, el negro', la cual se muestra en la Tabla 1.

De acuerdo a Unanue, la posibilidad de eliminar las diferencias a través de la educación y la moral colisionaban con la posibilidad de concebir hijos con 'moustrosidades', tal como lo muestra en el siguiente relato que aparece como un comentario a pie de página de la tabla anterior, en referencia al mulato:

"Este ente medio entre el blanco y negro legítimo atrae con mucha fuerza la atención del filósofo. La naturaleza se ha complacido en que a veces en el mulato entren por iguales partes el color blanco y el negro. En Londres hubo un hombre, hijo de europeo y de una negra, que tenía en el lado derecho el pelo y el color del padre, y en el izquierdo el de la madre: una línea dividía ambos en medio del cuerpo... Joan Clark hijo de un negro rico y de una inglesa, de la cabeza a la cintura era un hermoso inglés, de la cintura a los pies un feo africano..." $\left({ }^{4}\right)$

Cosamalón sostiene que esta cita de Unanue en donde se expresa la posibilidad de mutaciones ocasionadas por la mezcla racial es una metáfora que traduce un paralelo entre el mundo natural y el político

Es muy difícil percibir desde nuestra época la gran influencia que tenia en la mentalidad europea la visión negativa de diversos pensadores respecto al hombre americano. La influencia de De Pawn fue tal, que el propio Emmanuel Kant que en 1764 expresaba una alta consideración a los aborígenes americanos, solo 10 años después de haber leído a De Pawn, juzgaba a los indios una raza inferior. 
Tabla 1. De las diferentes castas que habitan en Lima, su origen, color y propiedades. El color blanco es el primitivo del hombre. Su última degeneración es el negro.

Conservación del color primitivo

regresos hacia él en sus degeneraciones

\begin{tabular}{lllll}
\multicolumn{2}{c}{ Enlace } & Hijos & Color & Mezcla \\
Varon & Muger & & & \\
Eur. & Eur. & Crio. & Bl. & \\
Crio. & Crio. & Crio. & Bl. & \\
Bl. & India & Mest. & Bl. & \\
Bl. & Mest. & Crio. & Bl. & \\
Bl. & Neg. & Mulato & & $1 / 2 \mathrm{Neg} .1 / 2 \mathrm{Bl}$. \\
Bl. & Mulato & Quart. & & $1 / 4 \mathrm{Neg} .3 / 4 \mathrm{Bl}$. \\
Bl. & Quart. & Quint. & & $1 / 8 \mathrm{Neg} .7 / 8 \mathrm{Bl}$. \\
Bl. & Quint. & Bl. & & \\
Neg. & India & Chino & &
\end{tabular}

Salta-atrás o degradaciones del color primitivo

\begin{tabular}{llllll} 
Enlace & Hijos & \multicolumn{2}{c}{ Mezclas } & Eur. & Europeo \\
Neg.Neg. & Neg. & & (6) & Crio. & Criollo \\
Neg.Mul. & Zamb. & 3/4 Neg. & $1 / 4 \mathrm{Bl}$. & Bl. & Blanco \\
Neg.Zam. & Zamb.Pto. & $7 / 8$ Neg. & $1 / 4 \mathrm{Bl}$. & Mest. & Mestizo \\
Neg.Zam.Pto. & Neg. & $15 / 16$ Neg. & $1 / 16 \mathrm{Bl}$. & Quart. & Quarteron \\
Neg.China & Zam. & & & Quint. & Quinteron \\
& & & & Zamb. & Zambo \\
& & & & Zam.Pto. Zamboprieto \\
& & & & Neg. & Negro
\end{tabular}

Unanue H. El Clima de Lima. Referencia 4.

y expresa el gran temor de las élites criollas respecto al mestizaje y la integración. Es decir, a malformaciones en el mundo natural le corresponden deformidades políticas. Esta metáfora expresa claramente una sociedad de castas donde cada uno tiene su lugar. La relación entre las castas, consagraba una sociedad piramidal, en la que españoles y criollos eran los señores, los indios campesinos y los negros, esclavos y sirvientes. Romper este dique podía ocasionar el desequilibrio del mundo natural, produciendo 'moustrosidades' naturales e incluso sociales $\left({ }^{8}\right)$.

Por todo lo anterior, la tabla de castas no debe ser entendida como una contradicción en el pensamiento de Unanue. Esta estratificación racial era expresión de una visión y de un orden social, donde aspectos raciales o étnicos fijaban los aspectos principales de las relaciones entre las clases incipientes $\left({ }^{9,10,11}\right)$. Estas se daban dentro de una compleja lógica estamental que se dio en las colonias españolas en América a partir del siglo XVIII y que expresó toda una corriente de construcción de identidad nacional y reformulación de las relaciones sociales y políticas impulsadas por las elites criollas americanas $\left({ }^{12}\right)$.

\section{La relación del ambiente con la propagación de las enfermedades}

Unanue basaba su concepción de los procesos de propagación en la unidad clima-ambiente-territorio. En este espacio específico, variaciones en las condiciones del clima pueden alterar el funcionamiento del cuerpo humano y los humores que lo componen. De otro lado, la interacción entre calor, humedad y materias orgánicas puede generar en la formación de aire o agua en estado de putrefacción, el cual al ser aspirado o ingerido podría propagar las enfermedades en la población. Los periodos de calor precedidos por inestabilidad climática, crean condiciones ideales para la propagación de enfermedades epidémicas como el sarampión y la viruela. Unanue, frente a los modelos europeos de degeneración física del nuevo mundo, que concibe un medio ambiente que produce seres físicamente inferiores, propone un universalismo climático, es decir un modelo de interacción general hombre-ambiente, frente al cual los habitantes del nuevo mundo pueden evitar la aparición de epidemias y mejorar las condiciones de vida de la población $\left({ }^{13}\right)$. Esta aproximación racional a la explicación y al control de los procesos de propagación de las enfermedades hace con toda justicia de Hipólito Unanue el fundador de la reflexión epidemiológica en el Perú.

Es importante tener en claro que la preocupación de Unanue por los problemas de población correspondía a un escenario donde confluían un proceso de crisis económica por el agotamiento progresivo de la producción minera y una caída importante en la población. Una epidemia, probablemente de Influenza que asoló el Virreynato del Perú entre 1720-1723, se estima que ocasionó unas 200000 muertes y fue la causa que se desarrollara el censo de población realizado bajo el gobierno del Marques de Castelfuerte y que se prolongó de 1725 a $1740\left({ }^{14}\right)$. Es muy importante tener en claro que la discusión respecto a la población y a la propagación de las enfermedades era parte del debate entre las élites criollas y metropolitanas y eran un componente de los procesos desencadenados por las reformas borbónicas orientadas a un fortalecimiento económico, militar y político del imperio español de ultramar $\left({ }^{15}\right)$. Estos procesos generaron la difusión de las doctrinas políticas y económicas que tuvieron amplia difusión en los sectores criollos $\left({ }^{16}\right)$, los cuales comenzaron a 
esbozar proyectos de sociedad y desarrollos alternativos a las contradicciones generadas por la última etapa de gobierno colonial $\left({ }^{17}\right)$.

Frente al hecho consumado de la independencia, las clases dominantes necesitaban garantizar que la naciente república continuara siendo una nación aristocrática y racialmente segregada bajo la conducción de las élites blancas de Lima ${ }^{\dagger}\left({ }^{18}\right)$. Es por ello que se observa en los ilustrados peruanos esta extraña combinación de proclamas de libertad y esclavitud, igualdad y elitismo, la dignidad de la persona humana y las tesis de diferencias naturales entre los hombres $\left({ }^{7}\right)$. Esta aparente contradicción es importante para entender la forma como los primeros epidemiólogos peruanos decodificaron y aplicaron en el siglo XX el pensamiento de Hipólito Unanue ${ }^{\ddagger}\left({ }^{19}\right)$.

La independencia trajo consigo el declive de la vida pública de las capas criollas que habían impulsado la reflexión sobre los temas poblacionales como parte de la discusión respecto a un proyecto de nuevo país. Si bien todavía continuaron por algún tiempo las ideas respecto a las constituciones epidémicas $\left({ }^{20}\right)$ y las relaciones entre la enfermedad y el clima $\left({ }^{21,22}\right)$, como lo demuestran los diversos estudios relacionados con las epidemias de la segunda mitad del siglo XIX, la reflexión epidemiológica local que predominó en dicho periodo fue sumamente incipiente y sin ninguna relación con los debates promovidos por la ilustración peruana. (Figura 2)

\section{La higiene y el proyecto de reconstrucción nacional de las élites de la posguerra}

Orden y progreso fue la esencia del nuevo proyecto de país a inicios del siglo XX. Luego de la guerra con Chile, las élites peruanas empiezan a definir de otra forma la nación peruana. Esta nueva definición se basó en la oposición de la cultura occidental respecto a la andina, la cual era percibida como inferior, además de ser un obstáculo para el progreso del país. La cultura y la tecnología de Europa eran sinónimos de progreso y desarrollo $\left({ }^{23}\right)$, constituyéndose el discurso científico en un eje fundamental del proyecto modernizador, lo cual brindaba a las élites un elemento de legitimidad frente a su descrédito por su fracaso en la conducción del país expresado por el desastre de la guerra. En ese contexto, los médicos tuvieron un papel relevante por su creciente prestigio al encarnar las posibilidades de progreso que la ciencia ofrecía. Sin embargo, su mirada no solamente estaba impregnada por el tamiz de la ciencia de occidente sino por el lugar preeminente que ocupaban en la sociedad.

El discurso médico, parte de la visión oficial, percibía al Perú como un espacio caótico, además de sucio e insalubre. Poblado en su mayoría por indios carentes de civilización, presas de absurdas creencias y costumbres ${ }^{\S}\left({ }^{24}\right)$; débil y despoblado. Se encontraba en los umbrales de la civilización (25,26).

Tal como lo describe Francisco Graña:

"El Perú es un país casi deshabitado. Pero no es todo. Algo más grave sucede todavía: El Perú no avanza, declina, ya que el desarrollo vegetativo de su población es nulo y como tal estacionarismo, efectivo, comprobado, resulta un retroceso real en el movimiento del progreso universal..." ${ }^{27}$ )

El interés de las élites en el tema poblacional era parte de una búsqueda de un proyecto de desarrollo que estaba fuertemente influenciado por pensamiento de economistas ingleses, como Douglas y Dalton, quienes evaluaron los retornos económicos de las intervenciones sanitarias en Inglaterra. Las posibilidades que ofrecía para el país estas políticas eran inmensas:

El destacado filósofo Sanmarquino Juan Abugattas remarca el papel central de Unanue en el diseño del nuevo orden postcolonial: "Unanue el más esclarecido de los ideólogos peruanos y también el más estructural de los conservadores, había comprendido mejor que nadie que en el Perú había pasta de grandeza. Conocía él perfectamente las riquezas y ventajas del territorio, pero sabía, a la vez, que tal grandeza no podía ser alcanzada bajo el liderazgo de los criollos: era a los indios y a las castas que correspondía ese destino. Tal destino, sin embargo, no podría cumplirse sino a costa de las minorías criollas y fue por ello que hubo que plantearse el reto de concebir una república criolla, excluyente y limitativa".

* Un ejemplo de cómo eran transparentes estas contradicciones para los primeros epidemiólogos las encontramos el análisis que hace Paz Soldán sobre las regulaciones sanitarias del trabajo de los esclavos al inicio de la república.

$\S \quad$ Avendaño al analizar el problema de la mortalidad infantil, describe el entorno en que nacen los niños de las 'clases menesterosas y vergonzantes': ... “Calcúlese las horribles escenas que se desarrollarán en los callejones y en las grandes casas de inquilinato, en albergues sucios y miserables, en donde figuran como actores una paciente rústica, rebelde por completo a toda práctica higiénica y una mujer estúpida que, con el atrevimiento que solo da la supina ignorancia, no vacila en sacrificar una o dos vidas en aras de unos pocos centavos que llega a arrancar a la familia de la incauta...". 


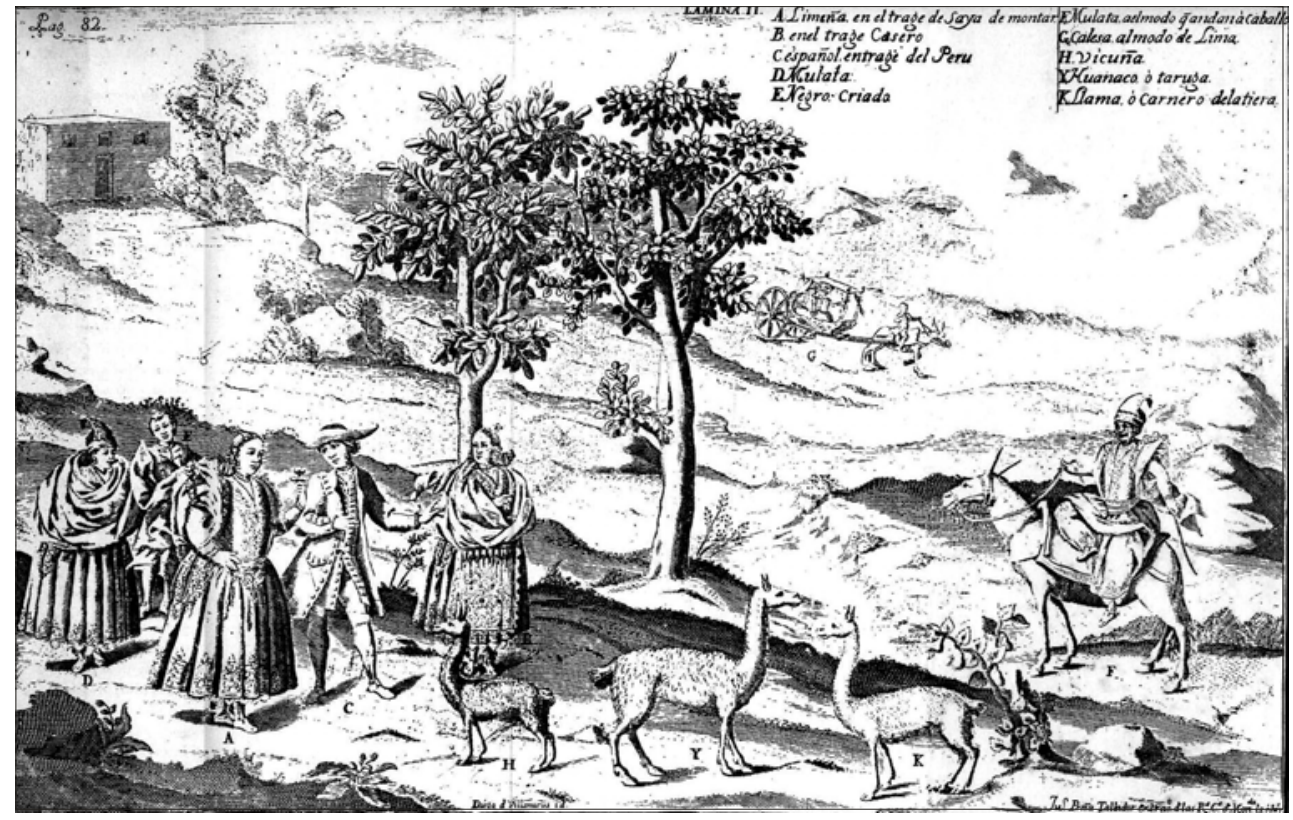

Figura 2. Antonio de Ulloa y Jorge Juan. Ilustración: Descripción de los habitantes del Perú. Relación histórica del viage a la

América Meridional, hecho de orden de S. Mag. para medir algunos grados de meridiano terrestre, y venir por ellos en conocimiento de la verdadera figura, y magnitude de la tierra, con otras varias observaciones astronómicas, y físicas (Madrid 1748, tomo III, página 82). El grabado, con las leyendas propias de los geógrafos de la ilustración muestra un orden natural del territorio, parte de ello, lo constituyen las castas que pueblan el Perú. Las descripciones de Antonio de Ulloa y Jorge Juan fueron muy sugestivas para los ilustrados peruanos. En su discurso 'Decadencia y Restauración del Perú', Unanue cita en varias oportunidades a Ulloa, de quien toma las vívidas imágenes de desolación y despoblamiento del país.

"Hoy el Perú parece decidido a seguir con fe y perseverancia el camino del progreso. Cuenta con elementos bastantes para alcanzar en el un puesto avanzado. A más de los recursos infinitos con que ha prodigado la naturaleza a nuestro suelo, poseemos las enseñanzas y la triste experiencia por la historia de casi un siglo de error y amargura. Es pues, ya tiempo de aprovechar tan ricos dones, de convertir en reales las riquezas que hasta hoy permanecen en estado potencial; para ello no nos es necesario inventar ni ideas, $\mathrm{ni}$ principios, ni métodos ni procedimientos, basta que querramos repetir lo que han hecho ya las demás naciones para llegar a la altura en que se encuentran..." (27)

A pesar de la certeza de que todo estaba escrito y definido, no tardó en emerger un debate, en el cual el punto central era en qué medida la población indígena, mayoritaria en el país, estaría en condiciones de ser la base para el desarrollo del Perú. Definir este punto era central dentro de las élites criollas que conducían el proyecto político de la república aristocrática. No es una casualidad que el discurso académico de la apertura del año académico 1916, en la Universidad Nacional de San Marcos, fuera realizado por Francisco Graña, catedrático de Higiene, quien sustentó el problema demográfico como central para el país en su alocución titulada: 'La Población del Perú a través de su historia' ${ }^{28}$ ).

En dicha alocución, Graña presenta la problemática del despoblamiento del Perú en torno a las diversas corrientes que desde 1915, comenzaron a difundirse activamente en la Universidad. En ese sentido, apareció un sector liderado por Carlos Enrique Paz Soldán y que incluía a intelectuales de la talla de Honorio Delgado, que promovía un discurso eugenésico estrictamente ceñido a las doctrinas de Galton $\left({ }^{29}\right)$. En su alocución, Graña presenta en oposición dos visiones respecto a la raza indígena. Algunos intelectuales, como Paz Soldán, consideraban que, al momento de la conquista, la población indígena era una raza decrépita y gastada, la cual estaba en un proceso de esterilidad progresiva, 
generadora de nuestro estancamiento demográfico. Otros, como José de la Riva Agüero, plateaban que dichos grupos humanos al momento de la conquista recién comenzaban su desarrollo y por lo tanto nada autorizaba a sostener la decadencia de las poblaciones originarias $\left({ }^{28}\right)$.

\section{Unanue como precursor de la Medicina Social}

Carlos Enrique Paz Soldán publica, en 1915, un artículo que resume su mirada de Hipólito Unanue como héroe cultural del naciente colectivo de higienistas, quienes se constituyeron en los iniciadores del discurso epidemiológico peruano:

"Al consignar con ocasión de la reimpresión de sus obras, la fecunda actividad de Unanue, creemos rendir un homenaje a su memoria, diciendo que fue un precursor afortunado de la Medicina Social. Su privilegiado talento le hizo vislumbrar que más allá de círculo estrecho de la medicina individual, estaba el campo grandioso de la medicina social. Por esto su actuación en el gobierno se caracterizó principalmente por sus actos de política sanitaria. Unanue creía, y creía con justicia, que la labor de un gobierno debe inspirarse en conceptos médico-sociales; que la protección de la salud y de la vida de los ciudadanos de un país es la primera medida de buen gobierno..." ${ }^{\left({ }^{30}\right)}$

Paz Soldán construye una imagen muy sugerente al mostrar cómo Unanue trasciende la mirada del individuo y logra introducirse a la salud colectiva a través de los ideales de buen gobierno y progreso social, que eran particularmente atractivos a las élites positivistas criollas de principios de siglo XX. Sin embargo, la influencia de Unanue en el naciente discurso epidemiológico iba más allá de la legitimidad que buscaba Paz Soldán entre las clases dirigentes para la introducción de un discurso de políticas sanitarias, como lo expresa de manera transparente en la introducción que escribiera para la reedición de 'El Clima de Lima':

"Defendió y persiguió tenazmente como una condición de mejoramiento y de orden la necesidad de poblar y cultivar en nuestro suelo al hombre sano, sin amenazas de la endemias y epidemias que ahora impiden el crecimiento nacional. Tuvo ideales eugenistas para el Perú, anticipándose así en más de medio siglo a los ideales acariciados después por el viejo continente..." ${ }^{\left({ }^{3}\right)}$

En ese sentido, Paz Soldán presenta a un Unanue, creador de la república y la medicina peruana, el cual desde su pensamiento fundacional legitima el discurso eugenista, de las élites dominantes. En ese sentido, la figura y la obra de Unanue, permitían una confluencia con las ideas promovidas por los primeros sanitaristas peruanos:

- El despoblamiento del Perú y la vulnerabilidad de sus habitantes azotados por endemias u epidemias.

- El tema racial, como un elemento explicativo de la propagación de las enfermedades.

- Un proyecto de desarrollo basado en la generación de procesos productivos en base a una masa crítica de población con un perfil sanitario y racial que permita el crecimiento y modernización del país.

Estas ideas eran parte del núcleo de pensamiento de quienes desplegaron explícitamente los primeros discursos epidemiológicos nacionales. Un ejemplo de ello es trabajo de Sebastián Lorente y Raúl Flores 'Estudios sobre Geografía Médica y Patología del Perú'. La trascendencia de este trabajo, por sus aportes a la construcción de una corriente de nacionalismo científico y al desarrollo de la epidemiología local, ha sido relevada por varios autores $\left.{ }^{32}\right)$. Sin embargo, se ha soslayado que uno de sus principales méritos lo constituye el transparentar el conjunto de ideas que animaba al naciente colectivo epidemiológico peruano.

Los autores, en el capítulo 'Breves apuntes sobre etnografia peruana, la población actual' hacen un extracto de las ideas de Carlos Enrique Paz Soldán, donde remarcan lo siguiente:

"Alejado, en cambio, del mundo civilizado por la enorme distancia y obstáculos poderosos; guardando en su territorio más que otra nación americana del sur una crecida cantidad de elementos pobladores autóctonos, restos del drama de la conquista hispánica, mezclada su cepa racial con todos los desechos de inmigraciones infames $y$, por último, privada de esas corrientes renovadoras de sangre blanca a las cuales debe su progreso buena parte del Nuevo Mundo, el Perú ofrece en estas angustiadas horas de crisis de la vida, en el problema de la raza, el primero y el más grave de todos los problemas nacionales...". ${ }^{\left({ }^{3}\right)}$

Respecto al indio, los autores recogen la siguiente cita de Paz Soldán: "En mayor número, constituyendo las cuatro quintas partes de la población nacional, está el indio, el sufrido, el triste e indiferente habitante de las cumbres nevadas de los andes y que sirve además de relleno, digámosle así, para colmar los vacíos de la población urbana y rural de los valles costeños". Respecto al estado sanitario de este grupo étnico refiere: "Es verdad 
que endemias desastrosas la asedian; que la falta total de hábitos de higiene, mina su robustez de otrora". Concluye al respecto de la raza blanca e india: "Indios y Blancos, he aquí las dos riberas que canalizan la corriente racial en nuestro país. Manchándola y dándola pigmentaciones imprevisibles para la Eugénica, están otras razas de activa participación en la dinámica etnográfica". $\left({ }^{33}\right)$

Al lado de los complejos problemas de la 'policromía racial', la cita de Paz Soldán recoge el viejo diagnóstico de crisis demográfica hecho por Unanue:

"Pero, al lado de esta policromía, que por sí sola es bastante para tornar pavoroso el problema que estudiamos, hay que señalar así mismo, un segundo factor que presta a la cuestión una gravedad que autorizaría a desesperar del porvenir. Y es la despoblación nacional. Cualquiera que haya estudiado las cifras reales o aproximadas de nuestra población, tendrá que suscribir la afirmación de que el Perú es un suelo sin hombres...". (33)

Estas citas de Paz Soldán que aparecen en la obra de Lorente y Flores, es más significativa en la medida de que el primero es el Director de Salubridad Pública y el segundo Director del Instituto Nacional de Vacuna y Sueroterapia y que dicho documento se produce a raíz de una Resolución Suprema firmada por Augusto B. Leguía el 10 de agosto de 1923, en que se demanda la elaboración de un instrumento para "la mejor orientación del plan sanitario que lleva a cabo el gobierno".

El consenso respecto al aporte de esta obra en su época fue muy importante, incluso para los sectores ideológicos más progresistas del país. José Carlos Mariátegui establece el siguiente juicio al respecto:

"En el prefacio de su libro, los doctores Lorente y Flores Córdova escriben que el panorama médico-social nos presenta en toda su magnitud y en toda su gravedad nuestro problema sanitario. 'Su estudio no exagera, en ningún caso, la realidad; tal vez, en alguno, la atenúa'. Lo que ensombrece el espiritu cuando se lee este volumen, -que ojalá arribara a las manos de todos los que tan fácilmente se equivocan respecto a la jerarquía o la gradación de los problemas nacionales, no es el juicio, moderado siempre, de los autores, sino el dato desnudo, la observación objetiva, la constatación anastigmática" ${ }^{(34)}$.

\section{Unanue el proto-epidemiólogo}

La amplitud del sistemismo que propone Unanue en el 'Clima de Lima' era perfectamente compatible con los ejes del pensamiento de las élites peruanas: Eugenia, Higiene Social y un proyecto modernizador. Paz Soldán, al hacer un sincretismo entre la higiene clásica y las diversas corrientes de la salud pública europea del siglo XX, encuentra en Unanue la posibilidad de hacer confluir sus postulados con la Medicina Social que impulsaba como proyecto de modernización del país. Por ello es que, en la introducción a la re-edición del Clima de Lima Paz Soldán señala respecto al libro:

"Cinco secciones distintas siguen a continuación, dando su materia al libro, que se diría un verdadero tratado de Medicina Social, entendida como el estudio del hombre en sus relaciones con los ambientes cósmico, geográfico y social, para conocer las leyes de la adaptación, de la perduración y de la perfección humanas...". $\left.{ }^{31}\right)$

El énfasis en lo poblacional aparece más tardíamente dentro de las lecturas que se hicieron del pensamiento de Unanue. Para un grupo de pioneros en la epidemiología, era más claro establecer una dimensión demográfico-poblacional en los aportes de su ilustre precursor; además, en esta línea de análisis era posible una continuidad de desarrollo, situación claramente transparentada por autores como Olaechea:

"Para juzgar mejor nuestra situación de hoy en el asunto de que me ocupo, considero útil estudiar nuestro desarrollo demográfico en el pasado, así como nuestra situación higiénica y asistencial entonces, mediante las opiniones que acerca de su deplorable condición y de los medios de salvarla formuló, con el preclaro talento que lo caracterizaba, el muy ilustre Hipólito Unanue, fundador de la Escuela de San Fernando...". ( ${ }^{35}$ )

A diferencia de Paz Soldán, que se centra en el 'Clima de Lima' para caracterizar a un Unanue sociólogo o epidemiólogo social, Olaechea se centra en analizar exhaustivamente las ideas de Unanue sobre la crisis demográfica peruana, expresadas en su discurso 'Decadencia y Restauración del Perú'. Si bien, el proceso de desarrollo propuesto por Unanue ya había sido superado por las corrientes teóricas de la economía política europea $\left({ }^{36}\right)$, esta visión de los procesos demográficos y su articulación con posibilidades de desarrollo fue muy sugerente e inspiradora para los primeros epidemiólogos peruanos, quienes la asumieron explícitamente. Así, cuando constatan el gran retardo del desarrollo demográfico del país refieren que:

"Las referidas conclusiones hacen ver que la grandiosa obra que el espíritu superior de Unanue quiso 
emprender para conseguir la ventura nacional, hace casi un siglo y cuarto, apenas si ha sido esbozada...Si las intenciones de Unanue no han tenido cumplimiento y ellas encierran de modo plenamente seguro la promesa de la prosperidad nacional, es evidente a quienes están persuadidos de la factibilidad de tal promesa, propender a que ella sea realidad...". ( $\left.{ }^{35}\right)$

Por ello, los primeros epidemiólogos peruanos tuvieron la impronta del poblacionismo de Unanue, donde las intervenciones de prevención y control de enfermedades transmisibles estaban orientadas a fomentar el crecimiento demográfico y mejorar las capacidades del capital humano del país. Durante la década del treinta, se observa la fuerte influencia de estas doctrinas en la concepción de las intervenciones sanitarias, tal como lo expresa Gamio al discutir los aspectos del control de la propagación de la Malaria en la costa peruana:

"No necesita mayor demostración el hecho de afirmar lo siguiente: El Perú es rico y está despoblado. Sus tierras cultivables esperan el brazo del hombre y del capital honrado. Su riqueza es geográficamente agropecuaria, nada más...luego, si el capital humano, el obrero del campo es reducido, al colmo, claro está, que debe ser todo un tema de política científica y de finalidad patriótica: el cuidar paternalmente, científicamente además el factor hombre en la agricultura nacional...debemos entonces, no sólo hacer indemne de epidemias y endemias curables a los valles agrícolas de la costa peruana, v gr., -sino también, deben ser finalidad primordial: el centuplicar la capacidad de trabajo muscular e intelectual de cada persona del campo y de la ciudad. He aquí el axioma que debe ser el lema de los patriotas conscientes, de los que proceden con conocimiento de causa...". ( $\left.{ }^{37}\right)$

No es casual que, luego de discutir extensamente diversos tópicos técnicos relacionados con la distribución de espacios ecológicos y su relación con la propagación de la malaria, el autor concluya con la siguiente opinión respecto a Hipólito Unanue:

"Este preclaro y eminentísimo sabio ariqueño -gloria de de la Medicina y letras clásicas del Perú-, sigue siendo un valor contemporáneo en grado supremo. Sus artículos, sus observaciones sobre Medicina Topográfica, Sociología, Geografía, Filosofía son admirables, profundas, claras, sencillas y desinteresadas. Están animados de un sabio y noble patriotismo, que hace recrear el espíritu con una sola lectura. Tenía el don genial de la previsión...". (37) (Figura 3)

Un estudio minucioso de la literatura relacionada con epidemiología y control de enfermedades entre la década del treinta y la primera mitad de la década del cuarenta, está fuertemente marcado por esta impronta de asimilación-decodificación de las ideas de Unanue a través de la Medicina Social proveniente de la Facultad de Medicina de San Fernando. Esta decodificación estaba orientada a legitimar a partir de la obra de Unanue, un discurso epidemiológico fuertemente influenciado por la Eugenia, donde la raza, era una de las categorías fundamentales para explicar la propagación de las enfermedades en el Perú, tal como lo expresa Paz Soldán al manifestar su crítica a las corrientes indigenistas emergentes en la década del 40:

"Para los que consideramos que lo fundamental de la vida de nuestros países es el problema biológico, ligado a lo social y movido por la herencia y el metabolismo, sobre lo que se afirma la cultura, conjunto de fuerzas imponderables a lo que por comodidad del léxico llamamos raza...". ( $\left.{ }^{38}\right)$

Un elemento tradicionalmente soslayado en la historia de la ciencia en el Perú es la fuerte influencia de la Eugenia, es decir la ciencia del estudio de las características y mejoramiento de los grupos raciales, el cual fue considerado por amplios sectores intelectuales como parte de una visión racional y científica del mundo. La epidemiología que se construye en un inicio en el Perú en base a la confluencia de diversas corrientes de pensamiento europeo, utilizó en un inicio la Eugenia como un factor explicativo de diversos procesos de propagación $\left({ }^{39,40}\right)$. De hecho, Paz Soldán fue un importante líder de opinión a nivel latino-americano en el campo de la Eugenesia $\left({ }^{41}\right)$ y a nivel local forma parte del colectivo que promueve la Primera Jornada Peruana de Eugenesia, donde este hace un puente entre las doctrinas eugénicas y el pensamiento de Unanue, al referirse durante el evento a la "Tradición insuperable sobre la raciogénesis que posee la Escuela Médica Peruana" $\left({ }^{42}\right)$.

Es muy importante entender también el contexto ideológico cultural que enfrentaron los primeros epidemiólogos peruanos. La Eugenesia era uno de los ejes de las políticas desarrollistas del primer mundo, que buscaba capitalizar las posibilidades de la ciencia en potenciar el desarrollo económico a través de mejoras cuantitativas y cualitativas en la población. En ese sentido, la eugenesia, como una expresión de la 'Ciencia Dura' de inicios del siglo veinte, fue todo un horizonte cultural que influyó la formulación de políticas públicas a escala mundial $\left({ }^{43}\right)$ e influyó notablemente en las élites 


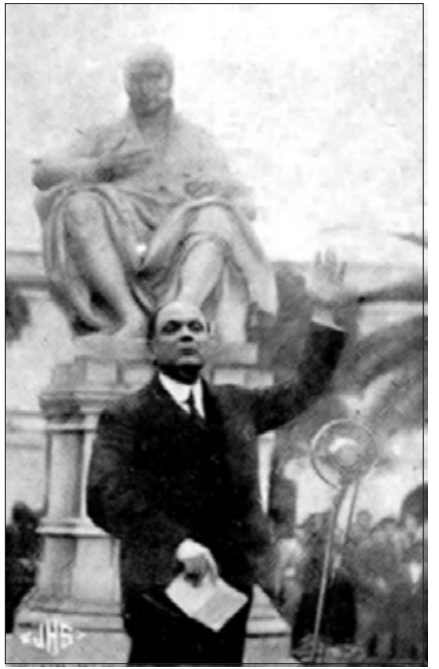

Figura 3. Carlos Enrique Paz Soldán en una alocución cívica en el parque universitario, Julio de 1938. La estatua que aparece la foto simboliza la gran impronta que tuvo Unanue como héroe cultural y referente conceptual para los higienistas que inician la reflexión epidemiológica peruana durante las primeras décadas del siglo XX.

políticas y científicas latinoamericanas $\left({ }^{44}\right)$. En dicho escenario cultural, no era posible desplegar una mirada a la sociedad desde lo 'técnico' sin pasar por la eugenesia. Solo en ese contexto es posible entender como la eugenia fue uno de los elementos sobre el cual se construyó los cimientos del naciente discurso epidemiológico peruano.

\section{Unanue y el análisis sistémico-ecológico a través del clima}

En una última etapa, los discursos epidemiológicos centrados en la construcción de una visión ecológicosistémica de los procesos de propagación reivindican el pensamiento de Unanue a partir de los efectos del clima y el medio ambiente en los procesos de propagación. Este énfasis aparece con Lastres, quien comienza a desarrollar un discurso progresivamente menos eugénico relevando la riqueza de las descripciones de Unanue de los diferentes espacios ecológico-geográficos del país, enfatizando su cercanía al Hipocratismo y a los clásicos (Galeno, Celso, Haen, Boerhave, etc.). Además, estableciendo una continuidad de pensamiento con Cosme Bueno y otros autores locales $\left({ }^{45}\right)$. Posteriormente, desarrollos conceptuales más avanzados, como el de Pedro Weiss, terminan de resaltar los aportes de Unanue en términos de descripciones geográficas e influencias del clima, eliminando todo componente eugenésico $\left({ }^{46,47}\right)$.

\section{Unanue como posibilidad de construcción de un pensamiento nacional}

Es importante señalar, como lo sostiene Cañizares, que la persistencia del pensamiento de Hipólito Unanue en torno a diversas interpretaciones permitió enlazar de manera creativa las influencias ilustradas europeas modernas con los prejuicios ideológicos y sociales de las élites del país, además de lograr articular una visión de futuro que perduró bajo diferentes máscaras en el desarrollo posterior de la sociedad peruana durante los dos últimos siglos $\left({ }^{36}\right)$.

Durante la primera mitad del siglo XX, el discurso epidemiológico fue parte de la reflexión de las élites peruanas en torno a los problemas de desarrollo de un proyecto nacional que permitiera el crecimiento y modernización del país manteniendo las diferencias estamentales que permitían el control de un estado y una economía oligárquica. En ese sentido, las primeras generaciones de epidemiólogos tuvieron que moverse en ese escenario cultural, para lograr legitimidad y poder sensibilizar a los grupos de poder frente a la necesidad de apoyar firmemente iniciativas orientadas a la mejoras de salud de la población $\|, \uparrow, * * *$ $\left({ }^{48,49,50}\right)$. Si bien la evolución del pensamiento de sus

II "Hay que proveer a la educación sanitaria de los dirigentes. Esta educación realizará el milagro de que cada cual esté en su sitio. El ministro, el parlamentario, el concejal, el socio de la Beneficencia, las autoridades políticas, el clero, el maestro, el abogado, el médico, el ingeniero, requieren de educación sanitaria...en este sentido la educación sanitaria debe ser considerada como un capítulo de la educación cívica...".

- Un ejemplo de los esfuerzos de los primeros epidemiólogos para promover en las élites acciones sanitarias concretas lo tenemos en la charla que realiza en el Rotary Club de Lima Carlos Enrique Paz Soldán, donde presenta ante su distinguido auditorio, las ventajas de las nuevas propuestas legislativas que obligaba a los empresarios y terratenientes a financiar un sistema de aseguramiento rural que permitiera el acceso a los trabajadores rurales al tratamiento contra la malaria.

** Marcos Cueto recoge el episodio de un debate entre un importante agricultor arrocero Gerardo Klinge y Carlos Enrique Paz Soldán en los salones de un club privado, frente a la resistencia de los agricultores con relación a la legislación que promovía la responsabilidad de los propietarios en el control de la Malaria en sus haciendas. 
principales actores, como Carlos Enrique Paz Soldán muestra un traslado paulatino hacia posiciones eugenésicas más incluyentes $\left({ }^{51}\right)$, también existieron retrocesos significativos, como las políticas etnocidas desplegadas por el proyecto de nacionalismo autoritario de Odría $\left({ }^{52}\right)$.

Consideramos que la evidencia mostrada hasta el presente nos permite plantear la hipótesis de que el nacionalismo, como un elemento dinamizador de la construcción de una tradición científica peruana, tuvo dos vertientes. La primera, establecida por varios autores, con las patologías nacionales, la verruga peruana y las enfermedades de altura, que estuvieron ligadas a corrientes culturales importantes como el Carrionismo y el Indigenismo, las cuales resumían un conjunto de reivindicaciones patrióticas y sociales $\left({ }^{53,54}\right)$. La segunda, sin embargo, provenía de las élites y planteaba la posibilidad de construcción de un discurso nacional que integrara nuestro legado colonial con la construcción de un nuevo país y encontraba en Unanue ese puente que permitía darle unidad a la imagen del Perú, tal como lo refiere Lastres al describir su obra:

"Exalta las cualidades del americano, en especial del peruano, de la tierra, donde la pródiga naturaleza ha esparcido con largueza sus productos: el Perú en quien reuniendo dos diferentes mundos se ha erigido en un templo digno de su inmensidad. Reclama un Perú ilustrado, pero con un espíritu liberal, cual convenía a un hombre de la ilustración. Se vale de la Historia, la Geografía, la Etnología y de la naciente Sociología, para dar un perfil definido a América y al hombre americano, en especial lo peruano. Adquiere el Perú por obra de este titán del espíritu, una personalidad de que carecía, un sentido de nacionalismo histórico, geográfico y biológico. Al rebatir con decisivos argumentos las débiles tesis de Buffón y De Paw, tiende un arco hacia la exaltación de los valores intrínsecos de lo americano y esto, diríamos, apunta hacia la independencia cultural del Nuevo Mundo. ¿No es esto, me pregunto, un anuncio vigoroso de la libertad de pensar, de formación de una conciencia peruana?...". ( ${ }^{(55)}$

En ese contexto, Unanue implicaba un proceso de construcción de identidad mucho más complejo, que estaba asociado a la formación de una 'conciencia peruana', es decir a una forma particular de mirar y transformar el mundo. Esta forma sistémica de abordar la complejidad del Perú, es justamente una de las características del desarrollo inicial de la epidemiología peruana, donde confluyen la Historia, la Geografía, la Sociología, la Antropología y por que no decirlo, la Eugenia para trazar explicaciones propias a los procesos de propagación de enfermedades en el Perú.

De otro lado, es importante entender el lugar de la sociedad, donde se inicia el discurso epidemiológico peruano de inicios del siglo XX. Graña, Paz Soldán, Lorente, Olaechea y otros ilustres higienistas formaban parte de la élite socio-cultural de la república oligárquica de la primera mitad del siglo XX y de la misma manera que Unanue, se vieron en la encrucijada de pensar el futuro y el desarrollo del Perú en medio de una sociedad de castas y de enormes fracturas sociales y culturales. Por ello, se observa en ellos las mismas contradicciones de los ilustrados de finales del siglo XVIII, que en la práctica lo único que hacen es expresar los límites de su visión del mundo y del proyecto fundacional de república de las élites criollas. Es importante señalar que, a la distancia es difícil ponderar el compromiso por el país, el inmenso valor y coraje que significó para estos ilustres peruanos impulsar el debate sobre muchos temas que abrieron camino para el desarrollo de políticas públicas orientadas a atender a las mayorías excluidas del país. El estigma conservador y racista que se ha levantado sobre algunos de ellos, específicamente sobre Paz Soldán, parte de una simplificación e incomprensión de las tradiciones culturales hegemónicas en la ciencia occidental y de los procesos complejos de decodificación de estos estilos de pensamiento, por parte de las sociedades estamentales latinoamericanas de inicios de siglo XX.

Por todo lo anterior, la influencia de Unanue en la naciente epidemiología es sumamente compleja y tiene varias dimensiones. Primero, la forma como las ideas de Unanue, padre de la medicina nacional y fundador de la república, brindaban legitimidad al discurso médico-social de Paz Soldán y al conjunto de higienistas de su generación ${ }^{\dagger \dagger}\left({ }^{56}\right)$. Esta legitimidad permitió una importante incidencia de dichas ideas,

${ }^{\dagger}$ La forma de encarnar esta legitimidad se expresa de manera transparente cuando en la Academia Nacional de Medicina su presidente Francisco Graña propuso que la Academia diera un voto declarando 'hijo directo de Unanue' al Secretario Perpetuo, Dr. Carlos Enrique Paz Soldán, por su constante superación en el servicio a la Academia. Una ovación cerró estas últimas palabras, quien enseguida declaró suspendida la sesión. Acta de la sesión solemne de transmisión de cargos, Lima 3 de febrero de 1939. 
que si bien fueron en un inicio funcionales al proyecto político de las élites, posibilitaron una mirada propia de los procesos de propagación de enfermedades. A pesar de la sostenida introducción de teorías y concepciones sanitarias provenientes del primer mundo, en el Perú, las primeras generaciones de epidemiólogos lograron el desarrollo de una mirada propia y a la vez original de la epidemiología, sincrética con occidente, a partir de nuestros propios problemas, con la certeza de ser parte de una tradición científica nacional. Esa posibilidad permitió, en un determinado momento, la aparición de diversas corrientes de pensamiento, donde se combinaron distintas disciplinas y le dieron a la epidemiología del Perú esa complejidad y riqueza de abordajes teóricos e instrumentales que permitieron su crecimiento y legitimidad, como disciplina y visión del mundo, alcanzado su máximo desarrollo en la década del cincuenta. Es a partir de ese periodo en que se observa una significativa caída de la reflexión epidemiológica peruana, la cual continúa hasta la actualidad, en parte por la forma como el colectivo local se ha ido alejando del desarrollo y discusión de propuestas de cambio alrededor de los problemas y contradicciones centrales de la sociedad peruana, lo cual constituye una de las mejores tradiciones y estilos de pensamiento de la epidemiología del Perú, soslayando la apuesta de los primeros epidemiólogos: la construcción de un proyecto de una nueva sociedad que permitiera cristalizar la vieja utopía de Unanue: la restauración del Perú, como un lugar donde todos los peruanos puedan cumplir sus sueños.

\section{Agradecimientos}

Mi profundo agradecimiento al apoyo y paciencia del personal de la Biblioteca de la Facultad de Medicina de la Universidad Nacional Mayor de San Marcos. Mi gratitud, una vez más, al Dr. Oswaldo Salaverry y al Dr. Gustavo Franco por sus comentarios y sugerencias.

\section{Referencias Bibliográficas}

1. Alarcón VJ. Corrientes del pensamiento epidemiológico en el Perú. Revista Peruana de Epidemiología. 1986;1(2):27-30.

2. Unanue H. Decadencia y Restauración del Perú. Oración Inaugural del Anfiteatro Anatómico, en la Real Universidad de San Marcos, el día 21 de noviembre de 1792. Obras Científicas y Literarias de Hipólito Unanue. Tomo II. p. 3-36.

3. Dager AJ. Hipólito Unanue en el Mercurio Peruano. Revista de Historia de América. 2001;128:98.

4. Unanue H. El Clima de Lima en Obras Científicas y Literarias de Hipólito Unanue. Tomo I. p. 3-203.
5. Gerbi A. Viejas Polémicas sobre el Nuevo Mundo. 3ra edición. Lima: 1946. p. 50-66.

6. Moyano B, Casas GA. Los discursos del encuentro y desencuentro surgidos en el primer contacto entre Europa y América. Revista Andaluza de Ciencias Sociales. 2003;3:6782.

7. León MA. El Clima de Lima y la reivindicación de las razas no europeas. La humanidad del indio. En: Castro A (ed). Filosofía y Sociedad en el Perú. Lima: Red para el Desarrollo de las Ciencias Sociales en el Perú; 2003. p. 41-61.

8. Cosamalón AJ. Amistades peligrosas: matrimonios indígenas y espacios de convivencia inter-racial (Lima 1795-1820). En: O'Phellan S, Compiladora. El Perú en el Siglo XVIII. La Era Borbónica. Lima: Instituto Riva Agüero, Pontificia Universidad Católica; 1999. p. 345-68.

9. Hernández M. ¿Es otro el rostro del Perú? Identidad, diversidad y cambio. Lima: Agenda Perú; 2000.

10. O’Toole RS. Castas y representación en Trujillo colonial. En: Drinot P, Garofalo L (editores). Más allá de la Dominación y la Resistencia. Estudios de historia peruana, siglos XVI-XX. $1^{\text {a }}$ ed. Lima: IEP; 2005. p. 48-76.

11. Rey de Castro AA. Ilustración y sociedad en el mundo iberoamericano: Elite y plebe, 1750-1821. En: Etnicidad y Discriminación Racial en la Historia del Perú. Tomo II. Lima: Instituto Riva Agüero, Pontificia Universidad Católica del Perú, Programa Sociedad Civil Banco Mundial; 2003. p. 111-46.

12. Cañizares EJ. Racial, Religious and Civic Creole Identity in Colonial Spanish America. American Literary History. 2005; 17(3):420-37.

13. Warren A. Piety and Danger: Popular Ritual, Epidemics and Medical Reforms in Lima; Peru, 1750-1860 [dissertation]. Dissertation submitted in partial satisfaction of the requirements for the degree of Doctor of Philosophy in History. San Diego: University of California; 2004. p. 196-204.

14. Pearce A. The Peruvian Population Census of 1725-1740. Latin American Research Review. 2001;36(1):69-104.

15. Fisher J. El Perú borbónico 1750-1824. $1^{\text {a }}$ ed. Lima: Instituto de Estudios Peruanos; 2000.

16. Ezquerra. La crítica española sobre América en el siglo XVIII. Revista de Indias. 1958;12(87-88):159-283.

17. Glick T. Science and Independence in Latin America (UIT Special Reference to New Granada). Hispanic American Historical Review. 1991;71(2):307-34.

18. Abugattas J. Indagaciones filosóficas sobre nuestro futuro. $1^{\text {a }}$ edición. Lima: UNMSM, UNESCO; 2005.

19. Paz Soldán CE. Hipólito Unanue y el Trabajo Agrícola de los Esclavos. La Reforma Mádica. 1935. p. 726-32.

20. Valdez JM. Memoria de las enfermedades epidémicas que padecieron en Lima el año 1821, estando sitiada por el ejército libertador. Lima: Universidad de San Marcos;1827.

21. Woodham J. The influence of Hipolito Unanue on Peruvian Medical Science, 1789-1820: A reappraisal. The Hispanic American Historical Review. 1970;50(4):693-714.

22. Lossio J. Acequias y Gallinazos. Salud ambiental en Lima del siglo XIX. Lima: Instituto de Estudios Peruanos; 2003. 
23. Marcone M. Indígenas e Inmigrantes durante la República Aristocrática: Población e Ideología Civilista. Historica. 1995;19(1):73-93.

24. Avendaño L. La Despoblación Nacional. Discurso de apertura del Año Académico. Lima: Universidad Nacional Mayor de San Marcos; 1901.

25. Wilson F. Indian Citizenship and the Discourse of Hygiene/ Disease in Nineteenth-Century Peru. Bulletin of Latin American Research. 2004;23(2):165-80.

26. Mannarelli ME. Limpias y Modernas. Género, Higiene y Cultura en la Lima del novecientos. $1^{\mathrm{a}}$ edición. Lima: Centro de la Mujer Peruana Flora Tristán; 1999. p. 47.

27. Graña F. La Cuestión Higiénica. [Tesis para optar el Grado de Bachiller en Medicina]. Lima: Universidad Nacional Mayor de San Marcos; 1903.

28. Graña F. La Población del Perú a través de la historia. Revista Universitaria. 1916;11(1):415-66.

29. Paz Soldán CE. La Medicina Social [Ensayo de Sistematización]. Lima: Universidad Mayor de San Marcos; 1916. p. 18-9.

30. Paz Soldán CE. La obra científica de un gran médico sociólogo. La Reforma Médica. 1915.

31. Paz Soldán CE. Observaciones sobre el Clima de Lima y su influencia en los seres organizados, en especial el hombre [Introducción]. 5ta edición popular. Lima: Comisión Nacional Peruana de Cooperación Intelectual; 1940.

32. Cueto M. Nationalism, Carrión's Disease and Medical Geography in the Peruvian Andes. Hist Phil Life Sci. 2003;25:319-35.

33. Lorente S, Flores CR. Estudios sobre Geografía Médica y Patología del Perú. Lima. 1925. p. 59.

34. Mariátegui JC. El Progreso Nacional y el Capital Humano. Mundial. Lima 9 de Octubre de 1925.

35. Olaechea A. Situación de la Sanidad y de la Asistencia en el Perú. Lima: Academia Peruana de Medicina; 1933.

36. Cañizares J. La utopía de Hipólito Unanue: comercio, naturaleza y religión en el Perú. En: Cueto M (ed). Saberes Andinos. Lima: Ciencia y Tecnología en Bolivia, Ecuador y Perú; 1995. p. 91-108.

37. Gamio E. Aspectos socio-geográficos del paludismo en la costa del Perú. Boletín de la Sociedad Geográfica de Lima. 1937; 54(1):41-54.

38. Paz Soldán CE. El Congreso de indianistas de Pátzcuaro y la mestización étnica, rumbo para la demogénesis americana. La Reforma Médica. $1^{\circ}$ de marzo de 1940. p. 142-5.

39. Paz Soldán CE. El Factor Hombre en Medicina Social, en La Medicina Social [Ensayo de Sistematización]. Lima: Universidad Mayor de San Marcos; 1919. p. 17-28.

40. Mendoza W, Martínez O. Las ideas eugenésicas en la creación del Instituto de Medicina Social. An Fac Med Lima. 1999;60(1):55-60.
41. Paz Soldán CE. La Eugenesia y sus posibilidades en América. Algunos conceptos sobre la genética humana o raciogenia en el nuevo mundo. Charla sustentada en la II Conferencia de Eugenesia y Homicultura. Buenos Aires, 25 de noviembre de 1934.

42. Congresos y Conferencias. Primera Jornada Peruana de Eugenesia. La Reforma Médica. 13 de mayo de 1939. p. 417-8.

43. Barrett D, Kurzman Ch. Globalizing Social Movement Theory: The case of Eugenics. Theory and Society. 2004;33:487-527.

44. Stepan N. The hour of eugenics. Race, Gender, and Nation in Latin América. Ithaca: Cornell University Press; 1991.

45. Lastres J. El pensamiento biológico de Unanue y algunas consideraciones sobre el Clima. Lima; 1933.

46. Weiss P. Ecología Médica. Adaptación. Revista de la Asociación de Estudiantes de Medicina Cayetano Heredia. 1965;2(2):3-21.

47. Murillo PJ. La obra de Pedro Weiss sobre la Enfermedad de Carrión: Una contribución al pensamiento epidemiológico nacional. Revista Peruana de Epidemiología. 1995;8(1):4250.

48. Valega J. La Educación Sanitaria de los Dirigentes. La Reforma Médica. 1ro de Enero de 1937. p. 41-4.

49. Paz Soldán CE. Suelo Sangre y Salud en la Costa Peruana. Algunas reflexiones sobre el problema de la Malaria en el Litoral. La Reforma Médica. 15 de Marzo de 1937. p. 245-8.

50. Cueto M. Identidad Nacional y Malaria en el Perú del siglo veinte. En: El Regreso de las Epidemias. Salud y Sociedad en el Perú del siglo XX. Lima: IEP; 1997. p. 127-71.

51. Paz Soldán CE. Una Doctrina y un templo. Biblioteca de Cultura Sanitaria. Lima: Instituto de Medicina Social; 1959.

52. Melgar BR. Nacionalismo autoritario y proyecto etnocida en Perú, 1948-1956. Cuadernos Americanos. 2002;(91):180-200.

53. Cueto M. Excelencia Científica en la Periferia. Actividades Científicas e Investigación Biomédica en el Perú 1890-1950. Lima: Grade-Concytec; 1989.

54. Murillo J, Salaverry O, Mendoza W, Franco G, Calderón W, Rodríguez-Tafur J. Daniel Alcides Carrión y su contribución al imaginario cultural de la medicina peruana. An Fac Med Lima. 2002;63(2):141-59.

55. Lastres J. El pensamiento científico-natural en el Perú a fines del siglo XVIII. Scientia. 1955. p. 1-8.

Manuscrito recibido el 15 de noviembre de 2005 y aceptado para publicación el 10 diciembre de 2005.

Correspondencia: Dr. Juan Pablo Murillo Peña

Apartado postal 75. Lima 5, Perú

Correo-e: epigroup@hotmail.com 